\title{
Online education in new period of sustainable development after the pandemic
}

\author{
Oksana Barabash ${ }^{1, *}$, Dmitry Sknarev ${ }^{1}$, Irina Maslova ${ }^{1}$, Marina Bereznyatskaya ${ }^{1}$, and \\ Alena Prakhova ${ }^{1}$ \\ ${ }^{1}$ People.s Friendship University of Russia (RUDN University), 6 Miklukho-Maklaya Street, Moscow, \\ 117198, Russian Federation
}

\begin{abstract}
The article is devoted to the problem of assessing the effectiveness of the online distance learning format, based on the results of work during the first wave of the COVID-19 pandemic. The purpose of the article is to identify specific problems faced by students of various education profiles: natural science and humanitarian. The objectives of the article are to analyze the scientific literature on the research topic, as well as present the results of the empirical research conducted by the authors among two groups of respondents. The methodology of the article is based on a systematic approach and includes a group of general scientific methods (analysis, synthesis, deduction, induction), as well as special methods: content analysis of scientific literature on the research topic, the method of sociological research (questionnaire survey), as well as the method of statistical analysis. Based on the results of the study, the authors came to the following conclusions: the online format of distance learning is not compatible with a number of natural science disciplines, which leads to a sharp decrease in the quality of education, especially in the field of applied sciences.
\end{abstract}

\section{Introduction}

The article is devoted to the problem of assessing the effectiveness for the online distance learning format, based on the results of work during the first wave of the COVID-19 pandemic. The article goal is to identify specific problems faced by students of various education profiles: natural science and humanitarian. The objectives of the article are to analyze the scientific literature on the research topic, as well as present the results of the empirical research conducted by the authors among two groups of respondents. The methodology of the article is based on a systematic approach and includes a group of general scientific methods (analysis, synthesis, deduction, induction), as well as special methods: content analysis of scientific literature on the research topic, the method of sociological research (questionnaire survey), and the method of statistical analysis. Based on the results of the study, the authors came to the following conclusions: the online format of distance learning is not compatible with a number of natural science disciplines, which leads to a sharp decrease in the quality of education, especially in the field of applied sciences. At the same

\footnotetext{
${ }^{*}$ Corresponding author: $\underline{\text { sknarev_ds@pfur.ru }}$
} 
time, the humanitarian spectrum of disciplines turned out to be more adaptive for the online format, which is confirmed by the results of a survey conducted among students of the humanitarian profile.

The relevance of the research topic is due to the fact that in the conditions of distance learning in the Russian education system, certain changes have occurred, the advantages and disadvantages of which must be assessed from the standpoint of improving programs and teaching methods during the new wave of the COVID-19 pandemic. The curricula and programs of many educational institutions include new types of learning activities that were previously used in a limited educational space, mainly in the framework of inclusive distance education. In particular, the online learning format has become necessary for lectures that are held remotely in order to ensure the continuity of the educational process. At the same time, certain assessments of the experience of online learning in the first period of the pandemic have already appeared in the scientific community, and many researchers note more problems than advantages of this format for mass education. In particular, one of the key difficulties that domestic analysts, teachers and university professors write about is the problem of incompatibility of the online format with the specifics of individual disciplines. For example, teachers of medical disciplines (surgery, anatomy, pharmacology, etc.) [1], teachers of geology, applied chemistry and many other natural sciences say about the impossibility of conducting online seminars, or rather about their complete inefficiency. disciplines of the practical spectrum [2].

The analysis of scientific literature carried out within the framework of the research topic showed that, in general, the humanities turned out to be more adaptive to mass online learning, however, a number of problems are also noted in this area: in language disciplines, in a number of art disciplines, as well as in those sciences, in which the physical presence of a teacher and a student in one space is necessary for the full development of the discipline (physical culture, choreography, music, vocals, etc.) [3]. In this regard, the generalization of the problems of online learning, as well as the experience of overcoming them, not only in domestic, but also in foreign pedagogical practice, are most relevant in the current situation of the second wave of the COVID-19 pandemic.

At present, the historiography of the issue, unfortunately, is not as extensive as one might have hoped. However, the issues of the applicability of online education for certain disciplines are discussed both in Russian and foreign science. In particular, among domestic works, one can single out the works of such authors as A.Yu. Alekseeva, Z.Z. Balkizov [1], V.G. Martynov, V.N. Koshelev, A.V. Dushin [2], I.A. Aleshkovsky, A.T. Gasparishvili, O. V. Krukhmaleva, N.P. Narbut, N.E. Savina [3], I.R. Gafurov, G.I. Ibragimov, A.M. Kalimullin, T.B. Alishev [4], Z. M. Kostoeva, L.R. Lolokhoeva, M.M. Kostoeva [5], E.N. Patrikova, T.S. Patrikova [6], E.N. Yudin [7]. Among the works of the empirical direction, one can single out the study of such authors as I.A. Aleshkovsky, A.T. Gasparishvili, O. V. Krukhmaleva, N.P. Narbut, N.E. Savina [3]. In foreign historiography, the problems of online learning are discussed in the works of such authors as P. Dlugosh [8], M.F. Henry, Cui Yuen, Mei Tsang [9], B.A. Olasile, M.O. Famolu [10], K.M. Rakshit Gouda [11].

Despite the available research in domestic and foreign science on online learning, it should be noted that there is a lack of a sufficient number of empirical works. The purpose of the article is to fill this historiographic gap by presenting empirically obtained data.

\section{Materials and methods}

The research methodology is based on a systematic approach and includes the methods of the general scientific group (analysis, synthesis, induction, deduction), as well as a number of special methods: historiographic analysis of scientific literature, the method of sociological research (questionnaire survey), as well as the method of statistical analysis. All 
data obtained in the course of empirical research was processed using the Neural Designer software, which is a tool for advanced descriptive and diagnostic analytics.

The research materials were the students' answers to the questions of two specially prepared questionnaires on the problems and advantages of online learning. The general sample of respondents was 150 people: 75 humanitarian students and 75 students studying natural sciences [12].

The survey was conducted on the social network VKontakte, since a classic field sociological study is impossible in the context of the COVID-19 pandemic. The study was conducted in the period from December 1 to 28, 2020 (collection of primary data), the results obtained were summarized from January 5 to 25,2021 . The study used a questionnaire containing 10 questions, the answers to which were assessed on a 10-point scale, then using the software for each questionnaire, the data were summed up and the average score was displayed. The higher the score, the higher the level of satisfaction with online learning among the respondents (1-3 low level, 4-6 - medium level, 7-10 - high level of satisfaction with training in this format) [13].

Questionnaire 1. Rate on a 10-point scale your attitude to the following questions:

1. How convenient is it to take a test / exam in an online format?

2. How informative are online lectures?

3. How convenient is it to get answers to questions about the lecture material from the teacher in the online format?

4. How clear and accessible is the material of the seminars in the online format?

5. How interesting is the online presentation of the material?

6. How effective do you think is studying your specialty online for your future professional career?

7. How psychologically comfortable is communication with a teacher in an online format?

8. How high is the scientific level of teaching your specialty online (teaching material, resources, etc.)?

9. To what extent is it necessary to use the online format to understand the essence of the main academic disciplines?

10. How confident are you about the correct understanding of the material presented in the online format?

\section{Results}

The total results for the answers of two groups of respondents (75 students in the natural sciences and 75 students in the humanities) are shown in Figure 1.

It is given according to the criterion of the specifics of the disciplines studied (compiled by the authors based on the results of the student survey) [14].

\section{Discussion}

Based on the data shown in Figure 1, we can say that students of the natural sciences did not rate online learning very high during the first wave of the pandemic: basically, an average score was put on all 10 questions of the questionnaire.

At the same time, the only advantage of this format of training, the students considered only the creativity of the presentation of the educational material, probably respecting the efforts of teachers in the difficult period of distance work. The students noted the following problems: the incompatibility of this format with the specifics of the specialty (answers to questions $6,9,10)$, as well as the lack of connection of the knowledge gained with real practical application in the future. This is an extremely alarming situation, especially for specialists vital to society (medicine, oil and gas education, geology, etc.). 


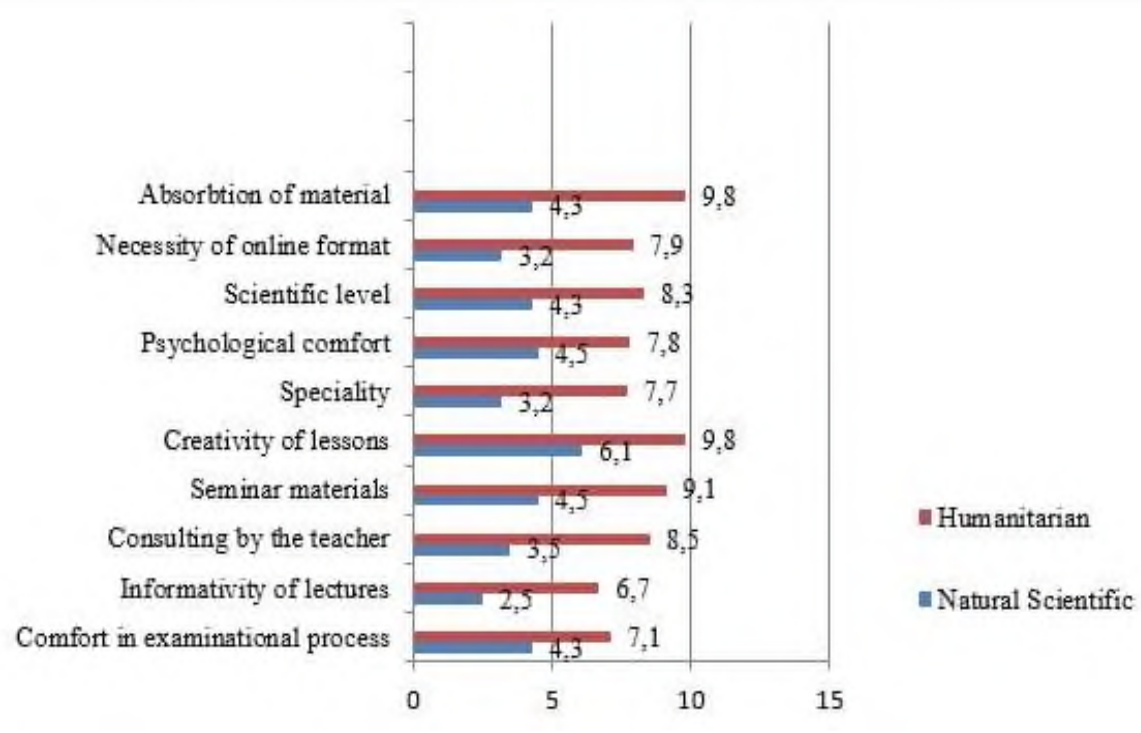

Fig. 1. Evaluation of the effectiveness of online learning after the first wave of the pandemic.

Unfortunately, in the online education mode, full-fledged training in such specialties of strategically important industries is impossible. This conclusion is confirmed by some earlier studies in Russian historiography [15-19].

Almost exactly the opposite picture developed in the group of respondents trained in the humanitarian profile. As can be judged from the data presented in Figure 1, the majority of respondents in the humanities profile are more optimistic about the possibilities of online learning, and the data obtained indicate only such problems as the informativeness of lectures, and evaluating this parameter, nevertheless, at the highest level.

Among the advantages of the online format, students noted almost all positions: creativity of the material, comfort, ease of passing the session, the scientific level of conducting classes, etc. At the same time, out of 75 respondents, only two gave an additional explanation in their questionnaires: "I like the fact that I can get an assignment and advice from a teacher at any time convenient to me" and "I liked the video lectures and online conferences most of all, because I find it difficult to perform in a real format in front of a large audience". In general, the results of training for the humanities were much higher in level than for the natural sciences [20-21].

\section{Conclusions}

Based on the results of the empirical study, the following conclusions can be drawn:

1) it is necessary to revise the curricula at universities in order to adjust the load in the online format for work in small groups, and not in lecture halls;

2) it is necessary to take into account the specifics of the specialty itself when conducting online classes, giving assignments of this kind so that students can independently complete them according to video instructions (excluding, of course, medicine);

3 ) in the context of a pandemic, the problem of the usefulness of seminars in the natural science sector of education also arose, which has not yet been resolved;

4) the humanitarian profile is more adaptive to the online format of education due to the specifics of the academic disciplines themselves, despite some problems for art history specialties, as noted in Russian historiography. 
The results of this empirical study need, of course, further verification from the point of view of further application of the online format for disciplines of various profiles.

This paper has been supported by the RUDN University Strategic Academic Leadership Program.

\section{References}

1. A.Yu. Alekseeva, Z.Z. Balkizov, Medical education during the COVID-19 pandemic: problems and solutions, Medical education and professional development 2, 8-24 (2020)

2. V.G. Martynov, V.N. Koshelev, A.V. Dushin, Modern challenge for oil and gas education, Higher education in Russia 12, 9-20 (2020)

3. I.A. Aleshkovsky, A.T. Gasparishvili, O.V. Krukhmaleva, et.al., Students of Russian universities on distance learning: assessment and opportunities, Higher education in Russia 10, 86-100 (2020)

4. I.R. Gafurov, G.I. Ibragimov, A.M. Kalimullin, T.B. Alishev, Transformation of education in higher education during a pandemic: pain points, Higher education in Russia 10, 101-112 (2020)

5. Z.M. Kostoeva, L.R. Lolokhoeva, M.M. Kostoeva, Distance learning: pros and cons, Bulletin of Science and Education 19, 76-78 (2020)

6. E.N. Patrikova, T.S. Patrikova, Features of the organization of modern training sessions with the use of distance educational technologies, Bulletin of the Tula State University. Technical science 1, 463-466 (2020)

7. E.N. Yudina, Experience of using distance education in the university, Science and school 5, 37-43 (2020)

8. P. Długosz, The pros and cons of distance learning for students from rural areas (2021) URL:https://www.researchgate.net/publication/348630077_The_pros_and_cons_of_dis tance_learning_for_students_from_rural_areas

9. M.F. Henry, C. Yuen, M. Tsang, Using Custom Textbooks as Distance Learning Materials: A Pilot Study in the OUHK. In book: Innovating Education in TechnologySupported Environments (2020)

10. B.A. Olasile, M.O. Famolu, Massive Open Online Courses: Pros \& Cons. (2020) URL: https://www.researchgate.net/publication/344941742_Massive_Open_Online_Courses _Pros_Cons

11. K.M. Rakshith Gowda, A study on distance learning in higher education during pandemic: challenges and opportunities (2020) URL: https://www.researchgate.net/publication/346647868_A_STUDY_ON_DISTANCE_L EARNING_IN_HIGHER_EDUCATION_DURING_PANDEMIC_CHALLENGES_A ND_OPPORTUNITIES

12. O. Grigorieva, Current trends in Russia's cooperation in the global organic market (legal aspects), E3S Web of Conferences 217, 07020 (2020)

13. E.Gaubas., T.Ceponis., D.Dobrovolskas., J.Mickevicius., J.Pavlov., V.Rumbauskas., Y.Vaitkus., S.Otajonov, N. Alimov, Study of polycrystalline CdTe films by contact and contactless pulsed photo-ionization spectroscopy, Journal Thin Solid Films 660, 231235 (2018)

14. V. Alpatov, A. Saharov, IOP Conf. Ser.: Mater. Sci. Eng. 661, 012086 (2019) doi:10.1088/1757-899X/661/1/012086 
15. I.S. Kholopov, M.I. Balzannikov, V.Yu. Alpatov, A.V. Soloviev, Girders of Hydraulic Gates Optimal Design, Procedia Engineering 153, 277-282, 1877-7058 (2016) https://doi.org/10.1016/j.proeng.2016.08.115

16. S.V. Veretekhina, S.V. Krapivka, O.L. Mnatsakanyan, I.I. Galin, S.V. Pivneva, Modern technology for evaluating measures to optimize and improve the working of teacher and staff, Journal of Physics: Conference Series 1691(1), 012197 (2020)

17. Y.G. Kokunko, S.A. Krasnova, S.V. Pivneva, Feedback Synthesis for UAVs Based on the Control Hierarchy Method Proceedings of 2020 15th International Conference on Stability and Oscillations of Nonlinear Control Systems (Pyatnitskiy's Conference), STAB 2020

18. V. Denisenko, E. Trikoz, Biopolitics and legal issues of emergency situations in the context of coronavirus pandemic, E3S Web of Conferences 175, 14013, 1-7 (2020) DOI: https://doi.org/10.1051/e3sconf/202017514013

19. A. Abashidze, E. Trikoz, The ICC Statute and the Ratification Saga in the States of the Commonwealth of Independent States, International Humanitarian Law Series 19, 1105 1110 (2009)

20. N.Kuzhel, A. Bieliatynskyi, O.Prentkovskis, I.Klymenko, Š.Mikaliūnas, E.Kolganova, S.Kornienko, V.Shutko, Methods for numerical calculation of parameters pertaining to the microscopic following-the-leader model of traffic flow: using the fast spline transformation, Transport. Vilnius (Lietuva): Technika 28(4), 413-419 (2013) DOI: 10.3846/16484142.2013.868369

21. O.Prentkovskis, A. Beljatynskij, E.Juodvalkienè, R. Prentkovski-enè, A Study of the Deflections of Metal Road Guardrail Post, The Baltic Journal of Road and Bridge Engineering. Vilnius (Lietuva): Technika 5, 2, 104-109 (2010) DOI: $10.3846 /$ bjrbe. 2010.15 